\title{
NILAI EKONOMI PEMANFAATAN IKAN NAPOLEON (Cheilinus Undulatus) DI KABUPATEN NATUNA, PROVINSI KEPULAUAN RIAU
}

\author{
Maulana Firdaus dan Rani Hafsaridewi \\ Balai Besar Penelitian Sosial Ekonomi Kelautan dan Perikanan \\ JI. KS. Tubun Petamburan VI Jakarta 10260 \\ Telp. (021) 53650162, Fax. (021)53650159 \\ Diterima 19 Februari 2012- Disetujui 24 Mei 2012
}

\begin{abstract}
ABSTRAK
Ikan Napoleon (Cheilinus undulatus) merupakan salah satu jenis ikan yang dilindungi karena populasinya yang terancam. Salah satu wilayah di Indonesia yang memiliki potensi ikan Napoleon adalah Kabupaten Natuna, Provinsi Kepulauan Riau. Eksploitasi ikan Napoleon di perairan tersebut tidak dapat dilakukan secara leluasa mengingat ada beberapa kebijakan pemerintah yang mengatur tentang tata cara pemanfaatan ikan ini. Tulisan ini bertujuan untuk memberikan gambaran mengenai bentuk pemanfaatan ikan Napoleon di Kabupaten Natuna, Provinsi Kepulauan Riau. Hasil kajian menunjukkan bahwa pemanfaatan ikan Napoleon di Kabupaten Natuna dilakukan melalui usaha penangkapan dan budidaya (pembesaran). Usaha pemanfaatan ikan Napoleon merupakan mata pencaharian utama masyarakat, karena harga jualnya yang tinggi. Kebijakan pemerintah terkait pemanfaatan ikan Napoleon adalah mengatur tentang tata cara penangkapan, ukuran yang diperbolehkan ditangkap dan pelarangan ekspor. Implementasi kebijakan ini harus mempertimbangkan dampak sosial ekonomi terhadap masyarakat, mengingat bahwa ada sebagian masyarakat yang menjadikan usaha penangkapan dan budidaya ikan Napoleon menjadi sumber ekonomi.
\end{abstract}

Kata kunci: nilai ekonomi, pemanfaatan, ikan napoleon, Kabupaten Natuna

Abstract : $\quad$ Economic Value of Napoleon Fish (Cheilinus undulatus)Utilization in Natuna Regency, Kepulauan Riau Province. By : Maulana Firdaus and Rani Hafsaridewi.

Napoleon fish (Cheilinus undulatus) is a protected fish due to its endangered population. Natuna Regency in Kepulauan Riau Province is one of the areas with high abundance of Napoleon fish resources in Indonesia. Exploitation of Napoleon fish in these areas became limitid activites since there are some government policies that regulate the procedures for utilizing this fish resource. This paper aims to provide an overview of utilization of Napoleon fish in Natuna Regency, Kepulauan Riau Province. This study results showed that utilization of Napoleon fish resources in Natuna Regency consist of catching and mariculture activitis. Utilizing of Napoleon fish has been main source of livelihood for the communities, because its high selling price. Government policies on utilization of Napoleon fish regulate fishing efforts procedures, size allowed to catched and export regulation. Implementation of these policies must consider the socio-economic impacts on society, because there are some communities utilized Napoleon fish catching and mariculture as their ecomomics source.

Keywords : economic value, utilization, napoleon, Natuna Regency

\section{PENDAHULUAN}

Ikan Napoleon (Cheilinus undulatus) adalah salah satu jenis ikan karang besar yang hidup pada daerah tropis. Panjang ikan ini dapat mencapai 1,5 meter dan berat dapat mencapai $180 \mathrm{~kg}$ dengan usia dapat mencapai 50 tahun. Kemampuan reproduksi ikan Napoleon sangat lambat. Kehidupan hewan ini umumnya sama dengan ikan karang lain yang hidup secara soliter di sekitar terumbu karang yang sehat. Bila terumbu karang mengalami kerusakan maka ikan ini berpindah ke lokasi terumbu karang yang masih sehat (Sadovy et al. 2003).

Ikan Napoleon dikenal sebagai salah satu komoditas unggulan yang memiliki nilai ekonomis tinggi. Sejak tahun 1990, permintaan ikan Napoleon sangat tinggi sehingga kegiatan penangkapan ikan
Napoleon di alam sangat intensif. Penangkapan ikan ini dilakukan dengan alat tangkap yang bersifat legal (jaring insang, pancing dan bubu) maupun ilegal (racun sianida dengan alat bantu kompresor). Sebagai akibatnya, populasi ikan jenis tersebut mengalami penurunan yang sangat signifikan sehingga International Union for the Conservation of Nature and Natural Resources (IUCN) menetapkan bahwa ikan Napoleon merupakan salah satu ikan yang dilindungi di dunia karena dianggap telah langka dan terancam populasinya di alam.

Pemanfaatan ikan Napoleon (Cheilinus undulatus) di Indonesia antara lain diatur dalam berbagai peraturan perundangan meliputi : (1) SK Menteri Perdagangan No.94/Kp/V/1995 tentang Larangan Ekspor Ikan Napoleon, (2) Keputusan Menteri Pertanian Nomor 375/Kpts/IK.250/5/1995 tentang Pelarangan Penangkapan Ikan Napoleon, (3) Keputusan Direktur 
Jenderal Perikanan Nomor: HK.330/S3.6631/96 tentang Perubahan Keputusan Direktur Jenderal Perikanan Nomor: HK.330/Dj.8259/95 tentang Ukuran, Lokasi dan Tatacara Penangkapan Ikan Napoleon. (4) Keputusan Menteri Kehutanan Nomor : 447/Kpts-II/2003 tentang Tata Usaha Pengambilan atau Penangkapan dan Peredaran Tumbuhan dan Satwa Liar dan (5) Peraturan Pemerintah Nomor: 8 Tahun 1999 tentang Pemanfaatan Jenis Tumbuhan dan Satwa Liar.

Salah satu wilayah di Indonesia yang memiliki potensi ikan Napoleon adalah di Kabupaten Natuna, Provinsi Kepulauan Riau. Nelayan tradisional di kabupaten ini menjadikan ikan Napoleon sebagai target utama penangkapan. Pemanfaatan sumberdaya ikan Napoleon yang dilakukan oleh masyarakat pesisir di Kabupaten Natuna harus mengacu kepada beberapa kebijakan pemerintah yang mengatur tentang tata cara pemanfaatan ikan ini. Kebijakan ini berimbas pada adanya pembatasan ruang gerak dalam pemanfaatan yang dilakukan. Tulisan ini bertujuan untuk memberikan gambaran mengenai bentuk pemanfaatan ikan Napoleon yang dilakukan oleh masyarakat pesisir di Kabupaten Natuna, Provinsi Kepulauan Riau.

\section{NILAI EKONOMI PEMANFAATAN IKAN NAPOLEON}

Kabupaten Natuna sebagai salah satu kabupaten di Provinsi Kepulauan Riau yang terdiri dari gugusan pulau memiliki sumberdaya perikanan yang sangat potensial. Bentuk pemanfaatan sumberdaya perikanan di wilayah Kabupaten Natuna dilakukan dengan cara usaha penangkapan dan budidaya laut. Beberapa jenis ikan ekonomis penting yang banyak ditangkap oleh nelayan antara lain adalah (1) kelompok jenis ikan demersal seperti berbagai jenis ikan kerapu (Cephalopholis sp) (kerapu tikus, kerapu bakau dan kerapu sunu), ikan Napoleon (Cheilinus undulatus), ikan Kurisi (Nemipterus sp) dan ikan Bambangan (Lutjanus sp), (2) kelompok jenis ikan pelagis seperti ikan Kembung (Rastrelliger sp), ikan Tongkol (Thunnus sp) dan ikan Tenggiri (Scomberomorus $s p)$, serta (3) kelompok crustacea seperti kepiting, udang dan lobster. Jenis-jenis ikan yang dibudidayakan di wilayah Kabupaten Natuna pada umumnya adalah ikan-ikan yang bernilai ekonomis tinggi seperti kelompok jenis ikan kerapu, lobster dan ikan Napoleon.
Ikan Napoleon merupakan jenis ikan primadona bagi nelayan dan pembudidaya di Kabupaten Natuna karena memiliki nilai ekonomi tinggi. Kegiatan penangkapan dan budidaya ikan Napoleon di Kabupaten Natuna salah satunya terfokus di wilayah Kecamatan Bunguran Barat. Berdasarkan hasil wawancara pada saat penelitian, kegiatan usaha penangkapan dan budidaya ikan Napoleon di Kecamatan Bunguran Barat telah berkembang sejak awal tahun 1990-an. Kegiatan usaha budidaya ikan Napoleon semakin meningkat pada awal tahun 2000. Hal ini tidak terlepas dari adanya pelarangan penebangan dan pemasaran hasil hutan di wilayah Kabupaten Natuna sehingga banyak pelaku usaha di sektor kehutanan beralih ke sektor perikanan untuk menjadi pembudidaya ikan Napoleon.

\section{- Usaha Penangkapan Ikan Napoleon}

Tingginya nilai ekonomi ikan Napoleon menyebabkan intensitas pemanfaatannya sangat tinggi di Kabupaten Natuna. Di Kecamatan Bunguran Barat, ikan Napoleon merupakan target utama penangkapan. Pada awalnya memang tidak ada nelayan yang secara khusus disebut sebagai nelayan Napoleon, karena ikan Napoleon yang tertangkap oleh nelayan bersifat sampingan (by catch) atau tidak sengaja tertangkap. Namun saat ini di Kecamatan Bunguran Barat terdapat nelayan yang mengkhususkan untuk menangkap ikan Napoleon.

Berdasarkan hasil wawancara, musim puncak penangkapan ikan Napoleon biasanya terjadi pada bulan November dan Desember (musim utara). Indikator yang dijadikan patokan sebagai musim puncak penangkapan yaitu berdasarkan banyaknya jumlah anakan (juvenile) ikan Napoleon yang ditemukan di sekitar terumbu karang pada bulan tersebut. Pada musim puncak, jumlah anakan (juvenile) ikan Napoleon yang ditangkap para nelayan dapat mencapai antara 20 sampai dengan 30 ekor dalam satu trip penangkapan. Nelayan melakukan penangkapan ikan Napoleon pada malam hari. Lamanya satu trip penangkapan berkisar antara 8 sampai dengan 12 jam.

Jenis alat tangkap yang digunakan oleh nelayan untuk menangkap ikan Napoleon antara lain adalah jaring, bubu dan pancing ulur. Juvenile ikan Napoleon (ukuran 1 - 2 inchi) ditangkap dengan menggunakan

Tabel 1. Alat Tangkap dan Ukuran Ikan Napoleon yang Tertangkap di Kabupaten Natuna Tahun 2011.

\begin{tabular}{|c|c|c|c|}
\hline No & Alat Tangkap & Ukuran Ikan & Keterangan \\
\hline 1 & Jaring & $1-2$ inchi & Ukuran mata jaring 0,5-1 inchi \\
\hline 2 & Bubu & $>4$ inchi ( \pm 100 gram) & \\
\hline 3 & Pancing Ulur & $>4$ inchi ( \pm 100 gram) & \\
\hline 4 & Sianida & $>4$ inchi $( \pm 100$ gram $)$ & \\
\hline
\end{tabular}

Sumber: Data Primer diolah (2011) 
alat tangkap jaring (ukuran mata jaring 0,5 - 1 inchi), sedangkan untuk alat tangkap bubu dan pancing ulur biasanya ukuran ikan Napoleon yang tertangkap adalah lebih dari 4 inchi (berat lebih dari 100 gram). Selain ketiga jenis alat tangkap tersebut ada juga sebagian kecil nelayan yang menangkap ikan Napoleon dengan menggunakan sianida (cyanide). Ikan Napoleon yang ditangkap dengan menggunakan sianida (cyanide) biasanya ikan Napoleon yang sudah berukuran besar, yaitu dengan berat lebih dari 100 gram. Alat tangkap dan ukuran ikan Napoleon yang ditangkap dapat dilihat pada Tabel 1.

Penangkapan ikan dengan menggunakan sianida (cyanide) dilakukan secara sembunyi-sembunyi oleh nelayan, karena termasuk bahan kimia yang dilarang digunakan untuk menangkap ikan. Persatuan kelompok nelayan yang ada di Kecamatan Bunguran Barat sangat menentang penggunaan sianida (cyanide) yang dilakukan oleh nelayan dalam menangkap ikan Napoleon maupun jenis ikan lainnya di wilayah perairan sekitar Kecamatan Bunguran Barat. Jika ada nelayan yang terbukti menggunakan sianida (cyanide) akan mendapatkan sanksi dari masyarakat berupa penyitaan kapal dan dilaporkan kepada aparat desa maupun penegak hukum.

Ikan Napoleon yang dijual dalam keadaan hidup akan lebih tinggi harganya jika sisiknya tidak rusak sedangkan ikan Napoleon yang dalam keadaan mati tidak akan laku untuk dijual. Biasanya nelayan akan membawa pulang ikan yang tidak terjual untuk dikonsumsi sendiri. Ikan Napoleon yang ditangkap oleh para nelayan dijual kepada para pembudidaya (pembesaran) ikan Napoleon yang ada di sekitar Kecamatan Bunguran Barat. Harga jual ikan Napoleon sangat bervariasi tergantung ukurannya (Tabel 2). Semakin besar ukurannya maka akan semakin mahal harganya. Ada dua jenis satuan atau ukuran yang digunakan oleh nelayan dalam menjual ikan Napoleon, yaitu berdasarkan berat (ons) atau panjang (inchi). Selain itu, harga ikan Napoleon juga sangat tergantung pada naik turunnya nilai tukar rupiah (Rp) terhadap dollar Amerika (US\$).

Jumlah rumah tangga perikanan yang bergerak pada usaha penangkapan di Kecamatan Bunguran Barat sampai dengan bulan Oktober 2011 adalah sebanyak 460 RTP. Jumlah keseluruhan armada adalah 515 unit yang terdiri dari 240 unit armada kapal motor dan 275 unit armada kapal tanpa motor. Armada penangkapan ikan yang digunakan adalah berukuran $<5$ GT untuk jenis perahu tanpa motor dan perahu motor tempel, sedangkan jenis armada ukuran 5 - 10 GT yang merupakan jenis kapal motor (mesin diesel). Secara keseluruhan, usaha penangkapan ikan di Kecamatan Bunguran Barat masih tergolong pada perikanan artisanal atau perikanan rakyat (small scale fisheries) yang beroperasi di wilayah perairan teritorial. Hal ini sesuai dengan kajian Dwiponggo et al (1988), bahwa sekitar 90\% perikanan tangkap di Indonesia baru berupa perikanan artisanal, sedangkan sisanya adalah perikanan maju atau komersil. Dahuri (2003), menegaskan jumlah perikanan artisanal di Indonesia mencapai 98,2\%.

Usaha penangkapan ikan yang dilakukan oleh nelayan di Kabupaten Natuna pada saat ini telah mengalami transisi dari skala usaha kecil (peasant fisher) menuju skala usaha menengah (post-peasant fisher). Hal ini sesuai dengan penjelasan Satria (2002), bahwa skala usaha kecil (peasant fisher) mempunyai ciri berorientasi untuk pemenuhan kebutuhan sendiri, menggunakan peralatan tradisional (dayung, melibatkan anggota keluarga sebagai tenaga kerja utama. Sedangkan skala usaha menengah (post-peasant fisher) menggunakan teknologi penangkapan kapal motor, masih beroperasi diwilayah pesisir pantai (teritorial), berorientasi pasar, tenaga kerja tidak lagi tergantung pada keluarga (Satria, 2002). Peningkatan skala usaha penangkapan ikan di Kabupaten Natuna dapat dilihat pada Gambar 1.

Mayoritas nelayan di Kabupaten Natuna mengetahui bahwa ikan Napoleon merupakan salah satu jenis ikan yang dilarang untuk ditangkap karena masuk dalam kategori langka dan dilindungi oleh negara sesuai dengan peraturan yang berlaku (SK Menteri Perdagangan No.94/Kp/V/1995, Keputusan Menteri Pertanian Nomor 375/Kpts/ IK.250/5/1995 dan Keputusan Direktur Jenderal Perikanan Nomor: HK.330/S3.6631/96). Namun pada kenyataanya para nelayan di Kabupaten Natuna, khususnya Kecamatan Bunguran Barat tetap melakukan penangkapan ikan Napoleon. Para nelayan beranggapan

Tabel 2. Harga Jual Ikan Napoleon Berdasarkan Ukuran di Kabupaten Natuna Tahun 2011.

\begin{tabular}{lll}
\hline No & \multicolumn{1}{c}{ Ukuran } & \multicolumn{1}{c}{ Harga (Rp/ekor) } \\
\hline 1 & 1 inchi & 50.000 \\
2 & 2 inchi & $70.000-120.000$ \\
3 & 4 inchi & 350.000 \\
4 & $0,5 \mathrm{~kg}$ & 500.000 \\
5 & $1 \mathrm{~kg}$ & $1.000 .000-1.500 .000$ \\
\hline
\end{tabular}

Sumber : Data Primer diolah (2011) 


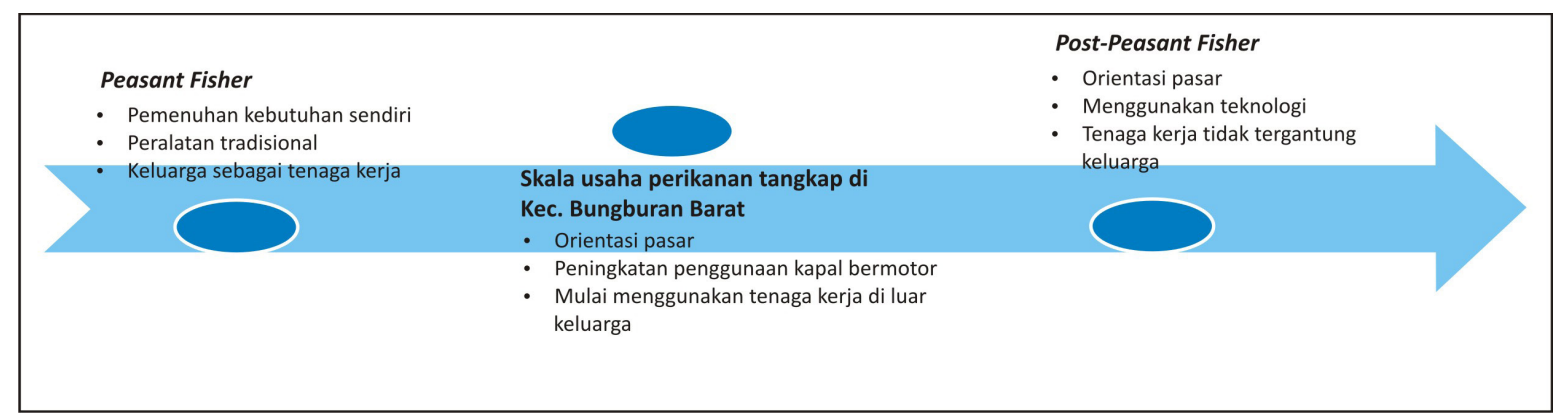

Gambar 1 . Peningkatan Skala Usaha Penangkapan Ikan di Kabupaten Natuna Tahun 2011.

Sumber : Data Primer (2011)

bahwa ikan Napoleon yang ada di wilayah mereka masih banyak, namun memang sulit untuk ditangkap. Upaya masyarakat (nelayan) untuk tetap menjaga kelestariannya yaitu dengan cara tidak menangkap dengan menggunakan alat tangkap yang merusak (seperti sianida dan trawl).

\section{- Usaha Budidaya Ikan Napoleon}

Usaha budidaya ikan Napoleon di Kabupaten Natuna salah satunya terfokus di Kecamatan Bunguran Barat, berupa usaha pembesaran ikan yang menjadi salah satu sumber mata pencaharian utama. Ikan Napoleon dipelihara dalam karamba. Ada dua jenis karamba yang digunakan oleh para pembudidaya yaitu karamba tancap dan karamba jaring apung. Mayoritas pembudidaya di Kecamatan Bunguran Barat menggunakan karamba tancap.

Usaha budidaya ikan Napoleon mulai berkembang pada awal tahun 2000. Karamba tancap yang digunakan memiliki ukuran yang bervariasi, antara lain dengan ukuran $2 \mathrm{~m} \times 3 \mathrm{~m}, 3 \mathrm{~m} \times 5 \mathrm{~m}$ dan $1,5 \mathrm{~m} \times 4 \mathrm{~m}$. Konstruksi utama karamba tancap terdiri dari kerangka yang biasanya terbuat dari kayu. Kemudian keramba tersusun atas jaring atau waring bagian atas dengan ukuran mata jaring (mesh size) sebesar 2 inchi atau 3 inchi dan jaring bagian bawah dengan ukuran mata jaring yang sama atau lebih besar. Ukuran mata jaring yang digunakan tidak selalu sama karena disesuaikan dengan ukuran benih yang ditebar pada keramba tersebut. Jika benih yang ditebar berukuran kecil, maka ukuran mata jaring yang digunakan juga kecil. Pada umumnya para pembudidaya memiliki lebih dari empat (4) unit petak karamba tancap yang juga dilengkapi dengan rumah jaga atau dikenal dengan istilah "camp".

Sampai dengan bulan Oktober tahun 2011, jumlah karamba tancap yang ada di Kecamatan Bunguran Barat yaitu sebanyak 225 unit dan jumlah karamba jaring apung sebanyak 1 unit (Dinas Kelautan dan Perikanan Kab. Natuna, 2011). Untuk setiap unit karamba tancap berbeda-beda jumlah petakannya, ada yang berjumlah empat (4) petak bahkan sampai dengan 20 petak per unitnya. Selain budidaya ikan Napoleon, masyarakat juga membudidayakan ikan jenis kerapu dalam karamba tancap.

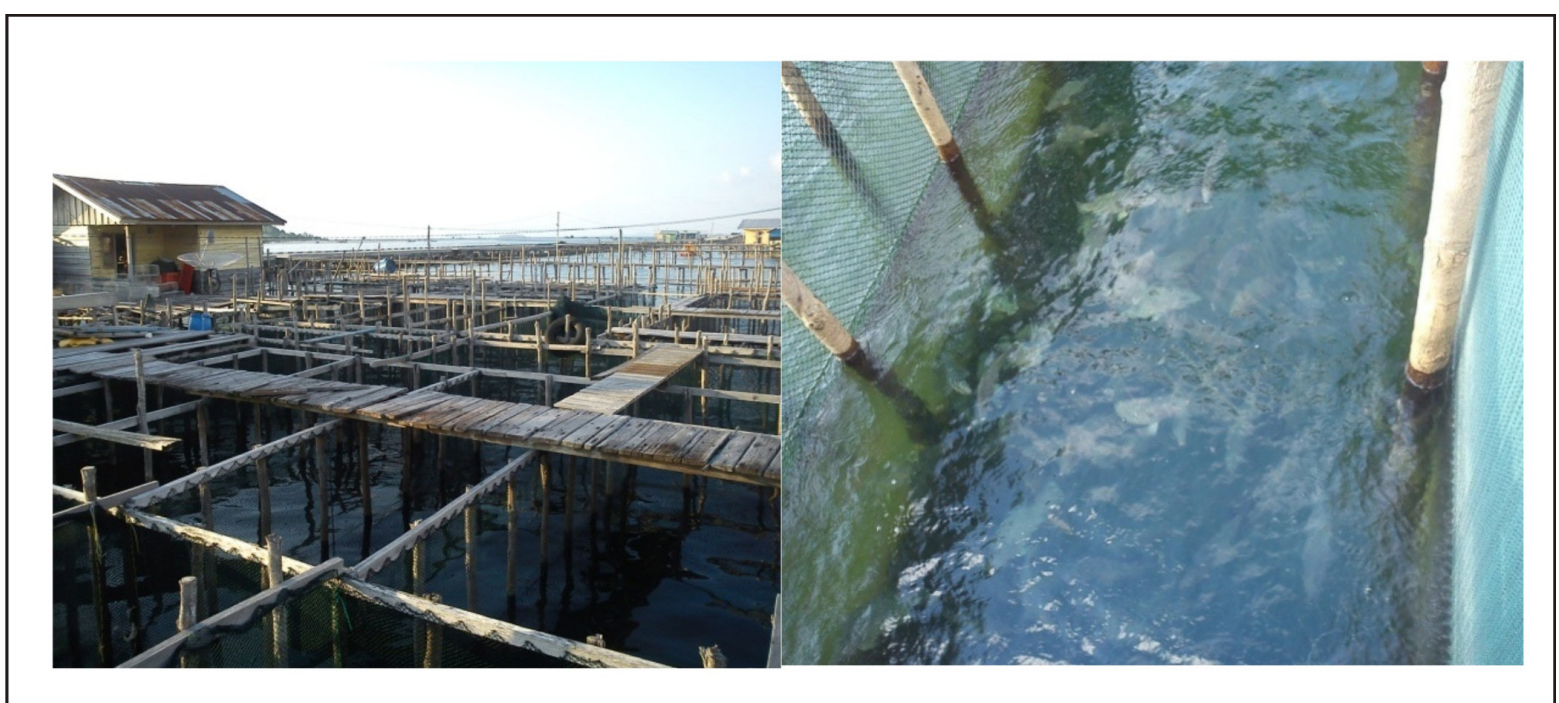

Gambar 2. Keramba Tancap Tempat Pembesaran Ikan Napoleon (Cheilinus undulatus) di Kecamatan Bunguran Barat, Kabupaten Natuna Tahun 2011.

Sumber : Dokumentasi Pribadi, 2011) 
Pembesaran ikan Napoleon dilakukan oleh masyarakat dengan tujuan komersial, sehingga pemeliharaan ikan dilakukan secara intensif baik dilihat dari padat tebar benih maupun pemberian pakannya. Untuk ukuran petak karamba tancap $2 \mathrm{~m} \times 3 \mathrm{~m}$ (tinggi 4 meter) dapat ditebar benih antara 50 sampai dengan 100 ekor benih. Ukuran benih berkisar antara 2 inchi sampai dengan 3 inchi. Pembudidaya pada umumnya memperoleh benih ikan Napoleon dengan cara membeli dari nelayan sekitar lokasi budidaya. Waktu pemeliharaan ikan Napoleon relatif lama, tergantung pada ukuran benih yang ditebar. Untuk ukuran benih 1 inchi sampai dengan 2 inchi waktu pemeliharaan berkisar antara 3-4 tahun. Untuk ukuran benih 4 inchi, waktu pemeliharaan dapat mencapai 2 tahun. Biasanya ikan Napoleon akan dipanen oleh pembudidaya jika beratnya sudah mencapai 8 ons/ekor atau lebih.

Usaha budidaya ikan Napoleon membutuhkan modal yang cukup besar. Investasi yang ditanamkan sebagai modal awalnya berkisar Rp 200.000.000,sampai dengan Rp 400.000.000,- per unit karamba. Investasi tersebut dikeluarkan untuk biaya pendirian karamba, jaring (waring), rumah jaga serta benih ikan Napoleon. Biaya operasional relatif kecil, meliputi biaya pakan dari awal sampai siap panen pada tahun keempat yang berkisar Rp 8.000.000 per petak karamba yang berisi 150 ekor ikan Napoleon (Haluan Riau, 2011)

Walaupun di Kabupaten Natuna terdapat usaha budidaya ikan Kerapu, namun mayoritas pembudidaya cenderung untuk membudidayakan ikan Napoleon dibandingkan ikan Kerapu maupun jenis ikan lainnya. Hal ini disebabkan karena (1) harga jual ikan Napoleon yang tinggi, (2) biaya operasional yang rendah dan (3) pemeliharaan yang mudah. Pakan yang diberikan berupa ikan rucah yang ketersediaannya di sekitar lokasi budidaya cukup melimpah sehingga pembudidaya tidak kesulitan dalam memperoleh pakan. Jika dibandingkan dengan biaya operasional budidaya ikan Kerapu, budidaya ikan Napoleon jauh lebih rendah, karena frekuensi pemberian pakan yang lebih sedikit dengan jenis pakan yang sama. Waktu pemberian pakan untuk ikan Napoleon dilakukan satu kali dalam sehari, yaitu di pagi hari (sekitar pukul 09.00) atau sore hari (sekitar pukul 16.00) yang biasanya pada saat kondisi air pasang.

Hasil budidaya ikan Napoleon di Kabupaten Natuna sebagian besar dibeli oleh orang asing (Hongkong) atau yang lebih dikenal dengan "Kapal Hongkong". Frekuensi pembelian ikan Napoleon yaitu sebanyak dua (2) kali dalam sebulan atau setiap dua minggu sekali. Menurut pembudidaya, selain membeli ikan Napoleon, "Kapal Hongkong" juga membeli ikan Kerapu. Jumlah ikan Napoleon yang dibeli lebih sedikit jika dibandingkan dengan ikan Kerapu karena terbatasnya pasokan ikan Napoleon. Kapasitas angkut Kapal Hongkong dapat mencapai dua ton. Menurut informasi yang diperoleh, dalam satu kali transaksi dapat mencapai Rp. 2.000.000.000,-. Ikan yang dibeli selanjutnya akan di pasarkan ke negara Cina dan Taiwan. Pemasaran ke Hongkong tidak dilakukan karena otoritas Hongkong melarang aktivitas perdagangan ikan Napoleon. Pada Tabel 3 memaparkan volume ekspor untuk jenis ikan Napoleon dan ikan hidup lainnya yang ada di Kabupaten Natuna.

Volume ekspor ikan Napoleon cenderung mengalami penurunan, bahkan pada tahun 2010 tidak ada laporan tentang ekspor ikan tersebut (Tabel 3). Berdasarkan hasil wawancara dengan Dinas Kelautan dan Perikanan Kabupaten Natuna, pada tahun 2010 memang untuk jenis ikan Napoleon sudah tidak dilakukan pencatatan lagi.

Permasalahan utama yang dihadapi dalam usaha pembesaran ikan Napoleon yang ada di Kecamatan Bunguran Barat adalah ketersediaan benih. Sejauh ini para pembudidaya membeli benih dari nelayan yang menangkap di alam. Jumlah benih yang dibutuhkan jauh lebih besar dari pada benih yang tersedia. Belum tentu setiap hari nelayan mendapatkan benih ikan Napoleon untuk dijual ke pembudidaya. Oleh karena benih yang tersedia terbatas, maka harganya menjadi cukup mahal yaitu mencapai Rp. 350.000,-/ekor untuk benih ukuran 4 inchi. Pada saat kondisi benih

Tabel 3. Volume Ekspor Berbagai Komoditas Ikan Hidup di Kabupaten Natuna Tahun 2008-2010.

\begin{tabular}{llcccc}
\hline \multirow{2}{*}{ No } & Jenis Ikan & \multicolumn{3}{c}{ Tahun } \\
\cline { 3 - 6 } & & $\mathbf{2 0 0 8}$ (ton) & $\mathbf{2 0 0 9}$ (ton) & $\mathbf{2 0 1 0}$ (ton) & Total (Ton) \\
\hline 1 & Ikan Kerapu Tikus/Bebek & - & 1,24 & 0,11 & 1,35 \\
2 & Kerapu Bakau/Tiger & 4,27 & 1,76 & 0,09 & 6,12 \\
3 & Kerapu Begak/Gepeng & 0 & 1,10 & 0,10 & 1,2 \\
4 & Ikan Ungar & 3,08 & 2,62 & 0,56 & 6,26 \\
5 & Kerapu Campur & 2,72 & 2,29 & 0,67 & 5,68 \\
6 & Kerapu sunu & 1,80 & 2,17 & 0,09 & 4,06 \\
7 & Ikan Napoleon & 1,07 & 0,12 & - & 1,19 \\
8 & Udang / Lobster & 0,09 & 0,18 & 0,47 & 0,74 \\
\hline
\end{tabular}

Sumber : Dinas Kelautan dan Perikanan Kabupaten Natuna (2010) 
ikan Napoleon langka dan untuk tetap menjaga keberlangsungan usahanya, sebagian pembudidaya di Kecamatan Bunguran Barat membeli benih dari luar daerah, yaitu dari wilayah Kepulauan Seribu, Provinsi DKI Jakarta.

\section{KESIMPULAN}

Sebagian besar masyarakat di Kabupaten Natuna menjadikan usaha penangkapan dan budidaya ikan Napoleon sebagai sumber penghidupan utama karena tingginya permintaan dan harga jual ikan Napoleon. Usaha penangkapan ikan Napoleon dilakukan oleh nelayan dengan menggunakan alat tangkap jaring, bubu, pancing ulur, sianida. Usaha budidaya yang dilakukan adalah pembesaran ikan dengan media dalam keramba jaring apung maupun karamba tancap. Benih ikan Napoleon berasal dari alam, yang diperoleh melalui nelayan, dengan lama pemeliharan berkisar antara 2 sampai dengan 4 tahun.

Penerapan kebijakan pemanfaatan ikan Napoleon, yang mengatur tentang tata cara penangkapan, ukuran yang diperbolehkan ditangkap dan pelarangan ekspor perlu mempertimbangkan dampak sosial ekonomi terhadap masyarakat, karena sebagian masyarakat di Indonesia menjadikan usaha penangkapan dan budidaya ikan Napoleon menjadi sumber penghidupan utama. Kebijakan yang dimaksud adalah; (i) SK Menteri Perdagangan No.94/Kp/V/1995 tentang Larangan Ekspor Ikan Napoleon; (ii) Keputusan Menteri Pertanian Nomor 375/Kpts/IK.250/5/1995 tentang Pelarangan Penangkapan Ikan Napoleon, serta; (iii) Keputusan Direktur Jenderal Perikanan Nomor: HK.330/S3.6631/96 tentang Perubahan Ukuran, Lokasi dan Tatacara Penangkapan Ikan Napoleon.

\section{DAFTAR PUSTAKA}

Dahuri, R. 2003. Pendayagunaan Sumber Daya Kelautan Untuk Kesejahteraan Rakyat. Lembaga Informasi dan Studi Pembangunan Indonesia (LISPI). Jakarta.

Dinas Kelautan dan Perikanan Kabupaten Natuna, 2010. Statistik Perikanan Tangkap Kabupaten Natuna 2010. Kabupaten Natuna. Provinsi Kepulauan Riau.

Jais, A. 2011. Ikan Napoleon Sedanau Fantastis. Haluan Riau. http:/www.haluanriau.com/2011/3/21/ ikan-Napoleon-sedanau-fantastis/diakses pada tanggal 10 November 2011.

Satria, A. 2002. Pengantar Sosiologi Masyarakat Peisisir. Cisendo. Jakarta.

Sadovy, Y., Kulbicki, M., Labrosse, P., Letourneur, Y., Lokani, P. \& Donaldson, T. J. 2003. The Humphead Wrasse, Cheilinus undulates: synopsis of a threatened an poorly known coral reef fish. Review in Fish Biology and Fisheries 13. 